\title{
A Call for Vaccine Against COVID-19: Implications for Cardiovascular Morbidity and Healthcare Utilization
}

\author{
Jamie S. Y. Ho ${ }^{1}$ Paul A. Tambyah ${ }^{2,3} \cdot$ Ching-Hui Sia ${ }^{3,4}$ \\ Published online: 8 May 2020 \\ (C) Springer Science+Business Media, LLC, part of Springer Nature 2020
}

Coronavirus disease 2019 (COVID-19) is an ongoing pandemic of SARS-CoV-2 infection with more than 1,000,000 cases and 50,000 deaths worldwide [1]. From large case series and cohort studies, it has emerged that cardiac injury and raised cardiac markers such as troponins I and T, creatine kinase-myocardial band and NT-proBNP occurs in 8-28\% of hospitalized patients, increasing to $28-51 \%$ in those with critical illness [1,2]. Cardiac injury is also associated with cardiovascular co-morbidities and increases risk of intensive care unit (ICU) admission, mechanical ventilation and mortality [2]. Patients with cardiovascular diseases such as ischemic heart disease and hypertension have an increased risk of severe disease and death. In those with cardiac injury, the risk of death is further increased compared with those without (69.4\%, 25 of 36 patients versus $13.3 \%, 2$ of 30 patients) [2].

The pathogenesis of severe COVID-19 disease involves a systemic inflammatory response causing release of inflammatory cytokines and cytokine storm. The resulting acute respiratory distress syndrome (ARDS) is a major cause of mortality [1]. ICU admission is associated with an increase in interleukin (IL)-2, IL-7, IL-10, granulocyte-colony stimulating factor, interferon- $\gamma$ inducible protein 10 , monocyte chemoattractant protein 1 , macrophage inflammatory protein $1-\alpha$ and tumour necrosis factor- $\alpha$. Systemic infection and inflammation may cause acute thrombosis by (1) direct activation of platelets, (2) acute coronary artery vasoconstriction due to sympathetic

Ching-Hui Sia

ching_hui_sia@nuhs.edu.sg

1 School of Clinical Medicine, University of Cambridge, Cambridge, UK

2 Division of Infectious Diseases, University Medicine Cluster, National University Hospital, Singapore, Singapore

3 Department of Medicine, Yong Loo Lin School of Medicine, National University of Singapore, Singapore, Singapore

4 Department of Cardiology, National University Heart Centre, 5 Lower Kent Ridge Rd, Singapore 119074, Singapore activity, (3) deregulation of coagulation system and (4) dysfunction of the endothelium. Hypoxemia and increased cardiac metabolic demand due to tachycardia may also worsen the cardiac ischemia.

Similar to COVID-19, influenza has been shown in many studies to be directly associated with adverse cardiovascular events caused by inflammation and infection (Table 1) including myocardial infarction [3], and myocarditis has also been reported for both influenza and SARS-CoV-2 infection. Overall, it is clear that viral respiratory infections may increase the risk of subsequent MI, and prevention of infection by vaccination may be a useful strategy in reducing acute cardiac events at the population level.

The influenza vaccine is part of the routine care of cardiovascular patients. Influenza vaccination has been associated with reduced coronary ischemic events with a 12-month event rate of $6.02 \%$ versus $9.97 \%$ in control group ( $p=0.047$ ), but not cardiovascular death $(0.63 \%$ vs $0.76 \%, p=0.95)$ [4]. A Cochrane review of 6 randomised controlled trials comparing influenza vaccination and control found that vaccination significantly reduced major cardiovascular events within 1 year of follow-up (2.9\% vs 4.7\%, RR0.64, $p=0,003$ ), but not death due to cardiovascular causes $(1.3 \%$ vs $1.7 \%$, RR0.81, $p=$ 0.61 ) [5]. Meta-analysis of secondary prevention trials did find a significant reduction in cardiovascular mortality (RR0.45, $p=0.003$ ) [6]. Due to the possible cardiovascular benefits and low risk of harm, influenza vaccination is still recommended by international guidelines in the prevention of cardiovascular disease in the elderly population and secondary prevention setting.Vaccination for COVID-19 is currently in development, with major international efforts from both public institutions and industry, but vaccine development only accounts for $3.7 \%$ of all COVID-19 trials [7]. At the time of writing, two vaccine candidates have entered phase I clinical trials (ChiCTR2000030906 and NCT04283461), and 42 are in the preclinical stages of research. The trials will be testing the safety, reactogenicity and immunogenicity of a recombinant adenoviral vector vaccine in one study and a 
Table 1 A comparison of COVID-19 and influenza in its characteristics, complications and pathogenesis

\begin{tabular}{|c|c|c|}
\hline & COVID-19 (SARS-CoV-2) & Influenza \\
\hline Case fatality rate & Around $3-4 \%$ & Around $0.1 \%$ \\
\hline Complications & $\begin{array}{l}\text { ARDS, RNAaemia, AKI, acute cardiac } \\
\text { injury, shock, rarely myocarditis }\end{array}$ & $\begin{array}{l}\text { ARDS, secondary bacterial } \\
\text { infection, rarely myocarditis, } \\
\text { neuromuscular effects }\end{array}$ \\
\hline $\begin{array}{l}\text { Pathogenesis of severe } \\
\text { disease }\end{array}$ & $\begin{array}{l}\text { Systemic inflammation, cytokine storm } \\
\text { (TNF } \alpha \text {, IFN, IL-2, IL-7, g-CSF, MCP-1, } \\
\text { MIP-1) and multi-organ failure }\end{array}$ & $\begin{array}{l}\text { Systemic inflammation, cytokine } \\
\text { storm (TNF } \alpha \text {, IFN, IL-1, IL-6, } \\
\text { IL-8, MCP-1, MIP-1) }\end{array}$ \\
\hline $\begin{array}{l}\text { Association with } \\
\text { myocardial infarction }\end{array}$ & $\begin{array}{l}\text { Maybe, cardiac injury may be caused by } \\
\text { MI or other causes }\end{array}$ & $\begin{array}{l}\text { Yes, across many studies and } \\
\text { meta-analysis }\end{array}$ \\
\hline Vaccination availability & $\begin{array}{l}\text { In development (ChiCTR2000030906 and } \\
\text { NCT04283461) }\end{array}$ & Yes \\
\hline $\begin{array}{l}\text { Vaccination association } \\
\text { with reduction in MI and } \\
\text { cardiovascular death }\end{array}$ & N/A & $\begin{array}{l}\text { Yes, across many studies and } \\
\text { meta-analysis }\end{array}$ \\
\hline
\end{tabular}

novel lipid nanoparticle-encapsulated mRNA-based vaccine in the other. A vaccine against this virus may play a role in the routine management of cardiovascular patients to reduce secondary events in this high-risk population similar to the influenza vaccine.

In addition to reducing the direct impact of MI due to COVID-19 on patients, preventing cardiac events has further implications on the healthcare system. In a statement from the American College of Cardiology Interventional Council [8], it is recommended that changes to the planning of cardiac catheterisations should be made to maximise the use of resources and minimise contamination. A dedicated catheterisation laboratory is advised for COVID-19 positive or suspected patients, and all staff should be fit tested for N95 masks and trained in PPE usage. In teaching hospitals, trainees and nonessential staff such as medical students should be minimised to reduce transmission risk and conserve PPE. If and when staffing levels are unable to meet the demand for the running of catheterisation laboratory, it may become necessary to use alternative strategies such as thrombolysis for the treatment of acute MI. Pre-emptively vaccinating healthcare staff against COVID-19 will thus conserve resources and help ensure continued provision of cardiovascular care. Reduction in acute presentations of MI may help alleviate pressures on acute care and intensive care units (ICU). Intensive care admission in COVID-19 is reported to be around 5\%, most commonly due to ARDS [1]. This results in a potential shortage of ICU beds for COVID-19 patients, and a reduction of ICU beds required for $\mathrm{MI}$ patients may allow repurposing of coronary care units to meet this demand.

COVID-19 is an unprecedented challenge to the health of many individuals and healthcare system of many countries. Current research and development of vaccines has led to much progress, and with further testing, they may halt the spread of morbidity and mortality caused by COVID-19 and its complications on cardiovascular disease and care provision.

\section{Compliance with Ethical Standards}

Conflict of interest None.

\section{References}

1. Clerkin KJ, Fried JA, Raikhelkar J, Sayer G, Griffin JM, Masoumi A, et al. Coronavirus disease 2019 (COVID-19) and cardiovascular disease. Circulation. 2020. https://doi.org/10.1161/ CIRCULATIONAHA.120.046941.

2. Guo T, Fan Y, Chen M, Wu X, Zhang L, He T, et al. Cardiovascular implications of fatal outcomes of patients with coronavirus disease 2019 (COVID-19). JAMA Cardiol. 2020. https://doi.org/10.1001/ jamacardio.2020.1017.

3. Kwong JC, Schwartz KL, Campitelli MA, Chung H, Crowcroft NS, Karnauchow T, et al. Acute myocardial infarction after laboratoryconfirmed influenza infection. N Engl J Med. 2018;378(4):345-53.

4. Ciszewski A, Bilinska ZT, Brydak LB, Kepka C, Kruk M, Romanowska $\mathrm{M}$, et al. Influenza vaccination in secondary prevention from coronary ischaemic events in coronary artery disease: FLUCAD study. Eur Heart J. 2008;29(11):1350-8.

5. Udell JA, Zawi R, Bhatt DL, Keshtkar-Jahromi M, Gaughran F, Phrommintikul A, et al. Association between influenza vaccination and cardiovascular outcomes in high-risk patients: a meta-analysis. JAMA. 2013;310(16):1711-20.

6. Clar C, Oseni Z, Flowers N, Keshtkar-Jahromi M, Rees K. Influenza vaccines for preventing cardiovascular disease. Cochrane Database Syst Rev. 2015;(5):CD005050. https://doi.org/10.1002/14651858. CD005050.pub3.

7. WCG (2020) Resource center: COVID-19 and clinical trial operations. https://www.wcgclinical.com/covid-19/? mkt tok= ey JpIjoi TnpabE1 HWT NOR 000 T 1d Jdy Is In Q i O iJ I 
Z0JXSVwvRVFWeWhXeEo2dU1XMGIxc3V6bFB NT2 ow MHJXWkVVSGtVVW sydWc0UkJcL1 Y x Y 3 JuUXB Y c284QkNMSDBrTkIzd1FFaU1HaVZGT0Z mWm 5 oej1TR 2 JuMjR1Nm1VTXA 0 eWRDVS sw V 0 t TejFNSFNyNEVvSXlcL2hZS3NzV01LViJ9. Accessed 4 Apr 2020.

8. Driggin E, Madhavan MV, Bikdeli B, Chuich T, Laracy J, BondiZoccai G, et al. Cardiovascular considerations for patients, health care workers, and health systems during the coronavirus disease 2019 (COVID-19) pandemic. J Am Coll Cardiol. 2020. https://doi. org/10.1016/j.jacc.2020.03.031.

Publisher's Note Springer Nature remains neutral with regard to jurisdictional claims in published maps and institutional affiliations. 